\title{
Retraction Note to: Spatial distribution of mountain soil environment and traditional village landscape based on image simulation
}

\author{
Jianjian $\mathrm{Li}^{1} \cdot \operatorname{Pan} \mathrm{Wei}^{1}$ \\ Published online: 6 December 2021 \\ (c) Saudi Society for Geosciences 2021
}

Retraction Note to: Arabian Journal of Geosciences (2021) 14: 1611 https://doi.org/10.1007/s12517-021-08014-1

The Editor-in-Chief and the Publisher have retracted this article because the content of this article is nonsensical. The peer review process was not carried out in accordance with the Publisher's peer review policy. The authors have not responded to correspondence regarding this retraction.

The original article can be found online at https://doi.org/10.1007/ s12517-021-08014-1.

Jianjian Li

2006010214@st.btbu.edu.cn

Pan Wei

2006010215@st.btbu.edu.cn

1 College of Art, Wuyi University, Wuyishan 354300, Fujian, China 